\title{
Clown Language Training in Dental Education: Dental Student's Perspective
}

Tevatia $\mathbf{S}^{*}$

Department of Periodontology and Oral Implantology, ITS Dental College, Muradnagar, Uttar Pradesh, India

Clowning is a form of humour. It is an art form that invites play, interaction, and laughter. Clown Care is a programme in hospitals and medical centres involving visits from specially trained hospital clowns. Clowning helps patients to focus on something other than their illness. Olsson et al. and Spitzer suggested that clown care could create a warm climate, promote good interpersonal relationships, and relieve feelings of frustration, anxiety, or hostility. Hospital clowns work worldwide as a health humanization resort, providing interplay with patients, family and staff creating a positive emotional state that fosters affirmative environmental conditions. This type of activity varies greatly in terms of professionalism, accountability and artistic methods. Promotion of emotional and psychosocial well-being of patients transcends opportunities for oral health promotion activities in hospitals, schools and community. Previous research reports on clown training reflects attitude-building potential for the healthcare students provided that it is performed in a deep, essential, strict and continuous fashion in a facultative manner rather than mandatory allowing the student to build his own artistic, professional and personal path. Thus, the prospect of introducing training curriculum of this underrated non-technical skill for dental students in Indian dental education system needs to be harnessed.
*Corresonding author: Tevatia S, Department of Periodontology and Oral Implantology, ITS Dental College, Muradnagar-201206, Uttar Pradesh, India, Tel: 01232225 381; E-mail: siddharthtevatia@gmail.com

Received March 21, 2017; Accepted March 23, 2017; Published March 25, 2017

Citation: Tevatia S (2017) Clown Language Training in Dental Education: Dental Student's Perspective. J Formul Sci Bioavailab 1: e101.

Copyright: @ 2017 Tevatia S. This is an open-access article distributed under the terms of the Creative Commons Attribution License, which permits unrestricted use, distribution, and reproduction in any medium, provided the original author and source are credited. 